\title{
Costa Rica's Development Strategy based on Human Capital and Technology: how it got there, the impact of Intel, and lessons for other countries
}

\author{
Andrés Rodríguez-Clare* \\ Written for the Human Development Report of 2001, UNDP \\ February 2001
}

\footnotetext{
* I wish to thank Danilo Arias, Armando Heilbrone, and Enrique Eggloff for the information, documents and opinions they shared. I also thank Miguel Angel Rodríguez for his helpful observations on a preliminary draft of this paper.
} 


\section{I - Arriving at a development strategy based on human capital and technology}

Over the last decade Costa Rica has experienced a tremendous leap forward in the development of a technology and knowledge-driven economy. ${ }^{1}$ Perhaps the better known part of this story is that an important group of high tech multinationals decided to establish manufacturing plants in the country. This group includes not only Intel and several other companies in the electronics sector (e.g., Remec, Sawtek, Conair, Reliability, Protek, Sensortronics, Colorplast), but also several companies in the medical devices sector, such as Abbott and Baxter. The country also appears to be benefiting from the IT led restructuring of large corporations, with the establishment of Procter and Gamble's Global Business Center in the country (the largest GBS in the world!), as well as other service centers such as Western Union and IT technical support provider Sykes.

The growing importance of knowledge and technology in the economy does not end with high tech multinationals, but reaches deeper into the economy, as evidenced by several domestic companies that are successfully competing worldwide in knowledgeintensive sectors. The clearest example is the phenomenal growth of the domestic software sector, thanks to which today Costa Rica has the highest software exports per capita in Latin America. Two very significant signals of the country's potential in software and design are associated with two recent decisions by Intel: first, it decided to invest in Costa Rica in the establishment of a center to develop software for the company and also to contribute in its semiconductor design processes, clearly moving beyond the assembly and testing operation it established just three years ago; second, through its venture capital fund, it invested in one of the most promising software companies in the country. All this goes together and is reinforced by the existence of

\footnotetext{
${ }^{1}$ Taking out the impact of Intel, a large part of which is an accounting matter with little impact on the real economy, Costa Rica's economy has been growing approximately 3\% per year from 1994 until 2000. This is barely above the rate of population growth, and approximately equal to the rate of growth of the labor force. Thus, this is not a period of high growth in labor productivity. This may seem a contradiction with the statement that Costa Rica has experienced a "tremendous leap forward" in its technological development. The explanation is that the new technologically advanced sectors are still a small part of the economy, and the last years have been difficult for the rest of the economy as a result of both internal problems (mainly a high fiscal deficit and an inefficient financial system, both of which translate into a high lending interest rate) and external problems (worsening terms of trade and adverse climatic conditions).
} 
internationally recognized centers of high quality training, education and research, such as Harvard-associate INCAE, Earth, CATIE, and INBio.

How did all this come about? What is the strategy behind it and how was it formulated? What explains Intel's decision to establish a plant in the country and how is this contributing to the economy's transformation into a knowledge-driven economy? What lessons, if any, are there for other countries that wish to pursue similar development goals? These are the questions that are explored in this paper.

\section{A national strategy?}

First of all, it should be emphasized that the positive technological developments experienced by Costa Rica in the last years are not the result of any collective and explicit decision. They are not the product of some charismatic leader who convinced the country to move in a particular direction. There is no specific legislation nor a "grand national vision" that is responsible for them. Moreover, there are important disagreements within the country about the measures, reforms and adjustments that have to be made for Costa Rica to be successful in this new stage of our development. There are profound divergences about, for instance, the role of the state and the private sector in the delivery of public services, most notably telecommunications. And this should be no surprise. One cannot expect an open and pluralistic democracy like Costa Rica to achieve the kind of long term and unified national vision that was found in countries like Japan, Taiwan and Singapore.

The fact is, as we will see below, that Costa Rica's recent string of achievements in the technological area are the result of a series of mutually reinforcing policies and events (some of them dating back to the $19^{\text {th }}$ century) that have converged in the last years. What is important, however, is that there is no significant opposition to a development strategy based on technology and human capital with high tech multinationals playing a key role. This is perhaps because there is no clear alternative to this strategy; or perhaps it is because the momentum accumulated over the last years behind these developments seems unstoppable. This momentum becomes evident when one sees several different institutions - from the national agency in charge of attracting foreign investment to the public universities, from the ministry of education to the national institution in charge of 
telecommunications - all moving ahead with programs and projects that in complementary ways support the transition of the economy towards the new knowledge-intensive stage.

\section{The role of history}

The process by which the country has arrived to its current "national strategy" started very early, even going back to the first half of the $19^{\text {th }}$ century, with the strong emphasis on education as the basis for democracy and development. Already at the beginning of the last century Costa Rica had a literacy rate that was among the highest in the Americas. This commitment to education was later reinforced with the creation of the first public university of the $20^{\text {th }}$ century in 1940 , later followed by the creation of three more in the 1970s. The public universities generated the supply of scientists and engineers needed for the industrial sectors that grew in the 1960s and 1970s under the import substitution model, and also for the state owned companies in telecommunications, electricity, agriculture, industry, water supply, and infrastructure.

The decade of the 1980s was worse than a "lost decade" for education in Costa Rica, as high-school enrollment rates fell significantly (only to recover to 1980 levels by the end of the 1990s), but there was one initiative which would later contribute significantly to the country's prospects for developing a technology and knowledge driven economy. This was the initiative to install computer labs in schools, a program that was later recognized around the world for two revolutionary characteristics: it concentrated on elementary schools, so that it could make a deeper impact on students; and it did not focus on teaching computer skills, but rather used the computer as a tool to aid in the general learning process. ${ }^{2}$

Without the investment in education that took place for almost two centuries, the current prospects for growth based on technology would of course be impossible. But this was, of course, insufficient. There is another part to the story that is more recent.

\footnotetext{
${ }^{2}$ During the 1970s and 1980s there were other developments in the educational sector that would also prove important for the new economy: the growth of private universities, and the creation of technical or vocational high schools and public Junior Colleges.
} 
After the crisis of the early 1980s, it became clear that the country had to abandon the import substitution model. The country then moved to an export promotion model, based primarily on trade liberalization (and access to the US market through the CBI) and two systems of fiscal incentives: the Export Processing Zone regime and the Export Contract. ${ }^{3}$

The Export Processing Zone regime allowed companies to import all their inputs and equipment tax free and avoid paying income tax for 8 years, paying only $50 \%$ of taxes due for the next 4 years. ${ }^{4}$ This system was designed to attract FDI and would eventually become one key element in the attraction of high tech multinationals. In fact, a study by FIAS (Foreign Investment Advisory Service, a joint service of the International Finance Corporation and The World Bank) concluded that Costa Rica's "free trade zone legislation has resulted in one of the better export processing zone systems in the developing world." (FIAS 1996, p. vi). ${ }^{5}$

Through the Export Contract, companies not only enjoyed an income tax holiday and tax free imports of equipment and inputs, but also received a generous subsidy equivalent to $10 \%$ of the value of their exports. This system was designed to help domestic companies change their strategy from one designed to the domestic and Central American Common Market towards one where they had to compete in open and competitive world markets. A parallel objective was to diversify the country's agricultural exports away from the heavy dependence on coffee and bananas. The subsidy was also justified as a way to compensate exporters for the inefficiencies in public services such as electricity, telecommunications, and ports, as well as the high costs of financial services like insurance and banking caused by the quasi-monopolistic structures that existed in those sectors.

The strategy of trade liberalization, export promotion and attraction of FDI paid off, and the country attained rates of growth in the second half of the 1980s and the early 1990s that were high relative to those experienced by other countries in the region. It soon became evident, however, that the system placed a heavy burden on the fiscal balance.

\footnotetext{
${ }^{3}$ In fact, fiscal incentives were important in making trade liberalization politically feasible.

${ }^{4}$ This system worked very well, the industrial parks were run by the private sector...

${ }^{5}$ In the year 1997, even before Intel started operations, exports from the EPZs accounted for more than one fifth of total exports (21.2\%). This shows the importance of EPZs in explaining the high export growth since the mid 80 s.
} 
The public debate that developed during the 1990s revolved around incentives, trade liberalization, and structural reform: the private sector argued that incentives and some degree of protection to local industry were necessary to compensate for the inefficiencies and distortions that existed in the country (mainly associated with the financial sector and public services like telecommunications and infrastructure). Economists and some policy makers argued that both incentives and distortions had to be eliminated simultaneously through structural reform. But the strong opposition from public sector unions and the political difficulties to pass reform bills through congress (given the lack of a strong majority for the governing party and the existence of congressional procedures that encouraged filibuster practices) made this very difficult and progress was frustratingly slow.

During these years of debates about structural reform, political candidates and governments talked about policies and programs to support science and technology, but there was little substance and little funding, leading to small programs with no significant impact on the economy. ${ }^{6}$ So neither the big debate in the political arena, nor the public policies related to science and technology did much to determine the new vision. What really made the difference was happening elsewhere, behind the doors of CINDE.

\section{The CINDE story}

The transition to the new export promotion model was accompanied and supported from the beginning by CINDE, a private non-profit organization, founded in 1983 by prominent business people, supported by the Costa Rican government and financed by grants from the US-AID. Its broad mission was to help in the development of the economy, but the attraction of FDI was always one of its top priorities.

Through time, CINDE gained very relevant expertise for FDI attraction, which it directed mainly towards agriculture and unskilled-labor intensive manufacturing sectors, specially apparel maquiladoras. The success it achieved was in large part due to

\footnotetext{
${ }^{6}$ The only exception is a project funded by an IDB loan approved in 1988, whose objectives were to strengthen the public universities' research capacities and to achieve a closer relation between such research and the needs of the productive sector.
} 
its institutional nature (non-political, non-governmental), which allowed it to have continuous programs and a long-term strategy, without being affected by periodic changes in government.

In the early 1990s CINDE realized that the country was losing competitiveness in unskilled-labor intensive industries to other members of the CBI and also due to the prospects for NAFTA, which would give Mexico a better access to the US market than the CBI members. At the same time, it was losing the sources of funding that it had enjoyed from its creation (US-AID). Given these circumstances, it decided to focus its FDI attraction efforts on fewer sectors, choosing the ones that were a better match for Costa Rica's relatively high education levels (i.e., skilled-labor intensive industries).

For the strategic plan for 1993, CINDE focused on sectors associated with the electrical, electronic and telecommunications industries. These sectors not only required more skilled workers, but were also experiencing fast growth in the US and strong competitive pressures were forcing companies to search for low cost locations around the world. It was thought that these sectors were a particularly good match for Costa Rica not only because of its good supply of technicians and engineers at relatively low cost, but also because of the widespread knowledge of English, the country's well known political stability and democracy, as well as a developed legal system (i.e., rule of law) and low levels of corruption. Moreover, there was a high quality of life, with good access to health services, nightlife and cultural amenities, and natural resources (for which the country was increasingly better known given the eco-tourism boom). In fact, there were already several companies in the electronics sector established in the country, among them Motorola, Trimpot, Sylvania, and Espion.

The year 1995 confirmed that this strategy was right. That year DSC Communications Corporation decided to establish a manufacturing plant in Costa Rica (the largest industrial investment in the country up until then). ${ }^{7}$ Sawtek Inc., Merrimac Industries, and Remec also chose to invest in the country. Thanks to these successes, CINDE acquired a deeper understanding of the industry, realizing for the first time that although Costa Rica had a unique competitive advantage for these sectors in relation to the other members of the $\mathrm{CBI}$, it was now competing against countries in other regions. In

\footnotetext{
${ }^{7}$ The investment by DSC was also significant because it was the first Printed Circuits Board (PCB) assembly plant in the country.
} 
addition to Mexico, El Salvador and the Dominican Republic, it was now competing against countries such as Ireland, Chile, Israel, and Thailand.

Thanks to this increased understanding of the electronics industry, CINDE learned that Intel was starting the site selection process for an assembly and testing plant for one of their newest chips. Given that Costa Rica was not on Intel's "long list" of possible sites, and not without some skepticism from their highest authorities, CINDE's specialists on FDI attraction started a campaign to make sure that it was included in the list. Thanks to the know how that CINDE had accumulated through many years of attracting FDI and through a few years of focusing on the electronics industry, they were able to put together an effective presentation of the country and finally enter the list in November of 1995 .

The next step was a visit from Intel to Costa Rica in April of 1996. After this visit, Costa Rica became one of the top contenders in the list, which at that stage included Argentina, Brazil, Chile, China, India, Indonesia, Korea, Mexico, Puerto Rico, Singapore, Taiwan, and Thailand. ${ }^{8}$ Having already three plants in Asia (Malaysia, China and Philippines), Intel decided it was necessary to diversify, so it dropped the Asian countries from the list. Additional research involving many visits by Intel representatives to the different locations narrowed down the list to just four countries: Brazil, Costa Rica, Chile and Mexico.

"Chile's lack of emphasis on the electronics sector and air transportation logistics made it an awkward strategic fit for Intel. Brazil, on the other hand, hat a lot to offer but Intel felt the business environment, at that time, would not be suited to the type of operation they were considering" (Spar, p. 10). Finally, Intel rejected Mexico because of its mandatory union rules and the fact that the incentives it offered were specific to Intel and somewhat discretionary, making them less credible and inferior to Costa Rica's more general and stable conditions. Intel finally announced its choice of Costa Rica on November of 1996.

\footnotetext{
${ }^{8}$ The best source of information about Intel's site-selection process is the FIAS study by Deborah Spar (Attracting High Tech Technology: Intel's Costa Rican Plant). For the purposes of this paper, I complement Spar's paper with personal interviews with Intel and CINDE representatives.
} 
Based on personal interviews and on the FIAS study by Deborah Spar (Attracting High Tech Technology: Intel's Costa Rican Plant), four factors emerge as the ones that made Intel choose Costa Rica for the location of its plant:

1) The general country characteristics provided a favorable basis to attract skilledintensive FDI: political and social stability; high quality of life; rule of law and low levels of corruption; relatively high levels of economic freedom, particularly with regards to international trade and capital flows; relatively high levels of education (specially engineers and technical operators) with acceptable knowledge of English at low cost; a non-union work environment; a "pro-business" environment with a favorable attitude towards FDI; a good package of incentives that had clearly defined procedures and conditions and was not subject to arbitrary negotiation (the EPZ system); and good location and transportation logistics.

2) The country's growing emphasis and success in attracting high tech FDI. This gave credibility to the case presented by CINDE and the Costa Rican Government that the country had the professional human resources required for an operation like the one Intel was planning. Furthermore, this allowed Intel to talk to representatives of several high tech multinationals with plants in the country when it visited the country in its site-selection process. According to Spar, the glowing reports and optimism of the executives at the Baxter and DSC plants were a decisive factor for Intel to put Costa Rica at one of the top positions of the list of countries it was considering for the investment.

3) The existence of an aggressive, effective and knowledgeable foreign investment promotion agency like CINDE. Not only was CINDE important in convincing Intel to consider Costa Rica as a possible location for its plant, but it was also extremely helpful to Intel in conducting its research and obtaining the credible and consistent information it demanded. Moreover, its links and credibility with the government allowed it to play a key role in arranging successful meetings between Intel executives and Government authorities.

4) A Government that quickly understood the importance of an Intel investment in the country. The president personally got involved not only in meeting Intel executives and conveying a very strong interest in its investment, but also in motivating and 
coordinating the rest of the Government to help Intel as much as they could within the limits of the laws and regulations that existed. In fact, the Government was very diligent in responding to Intel's concerns in areas like education, electricity and taxes. It most be point out, however, that the concessions made were not special to Intel, but were generally applicable to other companies as long as they met the required conditions. In this sense, it could be argued that these were not concessions, but rather Intel-inspired reforms to improve the country's competitiveness. ${ }^{9}$ This is perhaps the main reason why there was almost no opposition to Intel's investment nor to the incentives it received. ${ }^{10}$

With Intel's decision to establish its assembly and testing plant in the country, it became clear that attracting high tech multinationals was feasible and potentially effective as part of Costa Rica's development strategy. What was until then a CINDE strategy, became a national strategy.

\section{The FIAS study}

There was another important input in the definition of the high tech FDI attraction strategy. CINDE was clear that there were weaknesses in Costa Rica's economy that needed to be addressed if the country was to be successful in attracting FDI in electronics. Moreover, it was necessary to develop a deeper understanding of the electronics industry so as to make its FDI attraction efforts more effective. With this in

\footnotetext{
${ }^{9}$ Briefly, the reforms were the following. In the education area, they included the addition of a one-year "certificate" program focused on technical skills and physics/chemistry competency and a one-year "Associate Degree" program focused on semiconductor manufacturing. These reforms came from recommendations made by a special committee that was set-up for this purpose and was composed among others by the Minister of Education and the Minister of Science and Technology. In the area of electricity, the rates were very high, so the Government asked the regulator to establish a new lower rate for energyintensive industrial facilities. Finally, in the area of taxes, there was an ambiguity in the applicability of a new tax to companies in the EPZ system, so the government requested a formal interpretation from the Attorney General, which turned out favorable to Intel and other companies then entering to the EPZ system.

${ }^{10}$ In fact, when Intel's investment in Costa Rica was announced jointly with the Government, the President went out of his way to point out that Intel's decision was due to the many positive attributes of the country and its people, and not thanks to any special incentives or concessions given to the company. A few problems did arise later on, but these came not from opposition to the strategy of attracting hightech FDI, but were rather problems typically encountered during the construction of large manufacturing plants, such as neighbors' concerns about waste disposal and archeologists' concerns about protecting pre-Colombian ruins. Those concerns were dealt with very positively by Intel and public concerns were quickly put to rest by its "good citizen" behavior.
} 
mind, CINDE hired FIAS in 1996 to develop “A Strategy for Foreign Investment in

Costa Rica's Electronics Industry."

The study's main finding was that:

"There is a basis for substantial expansion of foreign direct investment in the electronics industry in Costa Rica... The niches for Costa Rica would not involve mass market products, but rather those with smaller production runs that require relatively large inputs of skilled labor for set-ups and testing. The most attractive niches can be grouped into four basic technology areas, as follows: power technologies, PC cards and surface mount technologies, system integration technologies, call centers... Such products draw heavily on the main advantage that Costa Rica has to offer the world electronics industry: this is the labor force that is relatively well educated in relation to its cost. The education advantage covers a wide range, from operatives to technicians and engineers. There is also a widespread knowledge of English... A number of the companies in CR are already producing power technology products, including transformers of various types... DSC Communications and a few other companies are already employing surface mount technologies in Costa Rica... Systems integration technologies put electronics together with other inputs to produce specific products (like medical devices)... Finally, the FIAS team feels that there is a substantial opportunity for developing call centers to support the electronics industry, as ACER is doing now."

The FIAS study also suggested promoting the sectors that support the electronics industry, such as plastics, metal working, mold making and equipment service and repair. This would help in the development of "clusters" and increase the country's competitiveness in these areas. The recommendation was that this should be done through FDI attraction in these areas as well as through backward linkage programs to develop such industries domestically. This, of course, was just the strategy that suggested itself after Intel decided to invest here.

Finally, FIAS noted several obstacles to the development of the electronics sector in the country. In particular, it noted weaknesses and recommended improvements in Intellectual Property Rights legislation, in telecommunications and transportation infrastructure, in the public system to support training, and also in the low quantity of technicians and engineers with English proficiency graduating from educational centers.

\section{From the FIAS study to the present}

CINDE accepted the FIAS study and used it for the definition of its strategic plan for the following years. In fact, for the 1997 plan CINDE stated its objective to position Costa Rica as "the emerging electronics manufacturing center in the Americas." The 
idea of fostering the development of clusters in certain skilled-intensive sectors was later reinforced by the "Competitiveness Agenda for Central America towards the $21^{\text {st }}$ Century" carried out jointly by INCAE and the Harvard Institute for International Development (led in this endeavor by Michael Porter and Jeffrey Sachs). This report emphasized the opportunities Costa Rica had in electronics and software and recommended the "cluster approach" to improve competitiveness in these areas.

In the following years, additional research allowed CINDE to continue improving and refining its high-tech FDI attraction strategy. This research led it to include the medical devices sector among its targeted sectors. Again, just as had happened earlier with the electronics sector, success came early, this time in the form of the decision by Abbott Laboratories to establish a sophisticated $\$ 60$ million manufacturing plant in the country in 1998 and Baxter's decision to expand its presence in the country with a $\$ 30$ million investment. New opportunities opened up later in the business services sector with Procter and Gamble's decision to establish a GBS for the Americas in the country, with the expectation of hiring up to 1,500 professionals.

Today, the country is following a strategy that appears to enjoy strong support from many different groups, and that includes not only CINDE's continuing efforts to attract high tech multinationals, but also an IDB-sponsored program to help SMEs become their suppliers and initiatives to improve the availability of the human resources needed for the new development model. ${ }^{11}$ This is complemented by more general policies that include improving telecommunications (specially for the Internet and data transmission), improving infrastructure through private sector participation, improving IPR protection (the required legislative changes have already been made in compliance with the Uruguay Round), and developing better access to foreign markets through free trade agreements with countries such as Mexico, Chile and Canada.

\footnotetext{
${ }^{11}$ Among these initiatives, worthy of comment are a large scale project financed by a grant from Taiwan to bring up to date the curricula and equipment for technical education in a few key sectors (informatics, electronics, metal working and mold making), ${ }^{11}$ and also the effort by public universities to increase and improve their programs for technicians, engineers and other professionals. This effort, it should be noted, receives strong support from Intel.
} 


\section{II - The Impact of Intel on Costa Rica ${ }^{12}$}

When Intel announced its decision to invest in Costa Rica, it projected its investment to be somewhere between $\$ 300$ and $\$ 500$ million. By December of 1999 , it had already invested \$390 million and was employing more than 2,200 people with wages much higher than the average wage in the manufacturing sector. ${ }^{13}$ For an economy with a GDP of less than \$13 billion in 1997 and a labor force of just above one million people, this was an extraordinarily large investment. In fact, in 1999 Intel accounted for more than $60 \%$ of the total growth experienced that year and almost $40 \%$ of total exports. Thanks to Intel's operation, the openness ratio (imports plus exports over GDP) increased from 70\% in 1997 to $83 \%$ in 1998 and in 1999 Costa Rica run a trade surplus for the first time in decades.

But all these effects are the ones anybody should expect from such a large investment in a small country. Of much more interest and relevance is the impact that Intel had on Costa Rica's ability to attract high tech FDI and on the economy's general competitiveness in skilled-intensive industries.

It is without question that having "Intel Inside" has helped Costa Rica's efforts in attracting high tech FDI. Intel's decision to invest in Costa Rica became news worldwide, and it tremendously improved the country's image as a viable economy and as an attractive investment location for high tech companies. In fact, in a survey carried out in 1999 among possible investors, 72 percent of respondents claimed that they had heard, seen, and read more about CR as an investment prospect after Intel's decision to set up a plant in the country (ARC, 1999). Given Intel's reputation for its rigorous siteselection research, other companies can in a sense "free ride" on Intel's research and be much more confident about investing in the country. "Intel Inside" became a credible "stamp of approval" for Costa Rica as a investment location. ${ }^{14}$

\footnotetext{
12 This section draws heavily from Larraín, López-Calva and Rodríguez-Clare (2001), complemented by interviews with Intel and CINDE personnel.

${ }^{13}$ As of September of 1999 , the average wage for Intel was $\$ 615$ whereas the average wage for the manufacturing sector was $\$ 406$. This, of course, is in large part due to the fact that Intel hires people with higher educational levels: out of the 2,217 workers it had at that time, more than 500 were professional employees, most of them engineers.

${ }^{14}$ Intel has also cooperated with CINDE in its efforts to attract certain large corporations to invest in Costa Rica. Companies such as Abbott and Procter and Gamble have done heavy benchmarking with Intel, validating CINDE's information with Intel's experience in the country.
} 
With this "stamp of approval" as its main selling point, CINDE launched a strong campaign to attract other large electronic manufacturers as well as Intel's worldwide suppliers to invest in Costa Rica. In fact, on the day that Intel announced its investment, the Minister of Foreign Trade predicted that the country could attract around 40 Intel satellite companies. The objective was not only to increase overall FDI but also to form the electronics cluster that was envisioned in the 1996 FIAS study and in INCAE/HIID's Competitiveness Agenda.

Unfortunately, the Asian Crisis of 1997 together with an industry downturn at a global scale significantly reduced the flows of FDI in the electronics sector. As an example of this, Seagate - a large scale manufacturer of hard-disk units - was forced to abandon its intent to establish a 5,000 employee manufacturing plant for which it had already bought the land. Advanced negotiations with Lucent also failed as a consequence.

Furthermore, many of Intel's suppliers refused to invest in the country on the basis that they would be selling to a single buyer. This made the investment too risky. ${ }^{15} \mathrm{~A}$ few Intel satellites did set up in the country. Examples are RVSI, NTK, Phillips, Magnéticos Toroid de Costa Rica, Tiros, Alphasem Corp., Delta Design S.A. and Esec USA, Inc. But most of these are small operations, with very few employees, and contribute little to the formation of the desired electronics cluster. ${ }^{16}$

All this should not in any way make the reader think that Intel did not generate a positive impact through backward linkages. On the contrary, in less than three years of operations, Intel has forced a significant improvement in the logistics area. As an example, FedEx and UPS have initiated operations in the country and thanks to that there are now daily cargo flights to several destinations in the United States. Moreover, AirExpress International, an international logistics and transportation company with a

\footnotetext{
${ }^{15}$ The largest Intel supplier that invested in Costa Rica was Photocircuits. In January of 1998, this company announced a $\$ 40$ million investment to produce the board on which Intel's semiconductors are mounted. The fast technological change characteristic of this industry, however, later led Intel to stop buying the boards from Photocircuits, providing a clear example of the risk involved in setting up a plant to supply a single buyer. As an interesting development, Photocircuits refused to close down operations completely, because it valued the workers it had hired and trained. It thus restructured its investment towards a center for the design of boards it produces in other locations.

${ }^{16}$ Another setback on the road towards the formation of the electronics cluster was the announcement by DSC Communications Corporation that it would close down its operation in the country. According to the statements made by the company, this in no way reflected a lack of competitiveness of the country, but rather obeyed the company's internal dynamics.
} 
close business relation with Intel, invested in the country through a joint venture with a local company.

Backward linkages have also developed through domestic companies that supply Intel with specialized goods and services. As a survey among Intel suppliers carried out by Larraín, López-Calva and Rodríguez-Clare (2001) shows, a significant percentage of Intel suppliers declared to have received training from Intel or to have changed their organizational practices or even to have introduced changes in their product variety due to Intel. A survey among Intel competitors in inputs markets (carried out by the same authors) reinforces the impression that Intel has generated changes in inputs markets from which other companies have also benefited. In fact, "eight firms maintained that some supplier of inputs had improved their quality after Intel's arrival, and specifically mentioned a certain type of service. As an example, packaging was mentioned as an input that had become more sophisticated in some specific firm, directly or indirectly due to Intel's demand for similar services." (Larraín et. al. (2001), p. 189). This second survey also revealed that most companies among those classified as Intel competitors in input markets thought that Intel had a positive effect on their own operations, and a very positive effect on the overall economy.

Apart from backward linkages, Intel has generated significant externalities through two other channels: training of its own workforce and support of educational programs in public universities. Intel invests heavily in the training of its employees, many of them even travel to and stay for several months at Intel's other plants. A significant part of this training is firm specific and Intel manages to keep turnover at a very low level, so only a small part of this training constitutes an externality. Still, one already hears of some "spin-offs," in which a few employees have quitted to set up their own operations, selling services to Intel and eventually to other local firms.

Perhaps the most important mechanism so far through which Intel has benefited the economy is in its collaboration with public universities to improve their curriculum and teacher training in technical fields. This has happened more intensively with the Instituto Tecnológico de Costa Rica (ITCR), which, under its "Intel Associate" status, has introduced new degree programs, has strengthened and updated its teachers' knowledge in several technical fields, and has improved its financial position. 
More generally, the mere presence of Intel in the country has increased the awareness about career opportunities in technical fields and engineering, leading to a very significant increase in enrollment in technical fields at public universities. "At the ITCR, for instance, the number of students enrolled in engineering fields grew from 577 in the first quarter of 1997 to 874 in the year 2000 , that is, from $9.5 \%$ to $12.5 \%$ of the total number of students enrolled" (Larraín et. al. (2001), p. 184).

To sum up, in only three years of operations in the country, Intel has had a strong beneficial impact on the country's competitiveness through its implicit "stamp of approval" on the country as an investment location for high tech multinationals and through its support of technical education in public universities. It has generated moderate benefits through backward linkages (both through leading a few of its satellites to set up in the country and through beneficial effects on domestic suppliers from which other domestic companies have benefited) and through externalities associated with labor training.

\section{III - Lessons for Other Countries}

We have seen that Costa Rica's recent string of successes in its transition towards a technology and knowledge-driven economy is the result not of an explicit and collective decision, or of a grand national vision that pointed in this direction, but rather it is the result of several different policies and events, some of them dating back to the $19^{\text {th }}$ century, that reinforced each other and converged in the last years. This makes it all the more difficult to extract specific lessons for other countries.

Still, some general observations may be of value to other countries:

First, it is clear that Costa Rica's long term commitment to investing in education has been the most important factor behind the recent developments. As the FIAS study confirmed, the country's main competitive advantage lies with a labor force that is well educated relative to its cost. Countries should not only focus on increasing coverage of primary and secondary education, but should also put in place technical high schools 
and universities that guarantee a steady stream of technicians and professionals in the areas where the country has a competitive advantage.

Second, many of the now dominant recommendations for economic development are validated: political and economic stability; rule of law, transparency and low levels of corruption; economic liberalization, both with regards to international flows of goods and capital; a "pro-business" environment with a favorable attitude towards FDI.

Third, it appears that the Export Processing Zone system was an important element in the attraction of FDI in the Costa Rican case. Yet, due to the Uruguay Round agreement to eliminate export subsidies by the year 2003 in all developing countries, other countries that want to adopt a similar strategy will have to do without this kind of incentives. One obvious alternative, but not without its costs, will be to establish aggressively low corporate income tax rates.

Fourth, CINDE played an essential role not only in attracting FDI but also in determining a strategy geared towards the electronics sector that would later prove successful for the country. The fact that it is a non-profit organization, with strong ties to both the private sector and the public sector, with no special relation to any interest group, with strong financial support, together with its apolitical nature, seems to have provided CINDE with the required characteristics to play such a profound role. Thanks to its nature, this organization was able to establish long term goals, do the required detailed and careful research, get the appropriate expertise and human resources, be selective in its approach towards FDI and make sure that its efforts matched the country's competitive strengths.

Fifth, looking at the recent development in Costa Rica, it seems that countries should carefully identify the sectors where the country has a strong competitive advantage and thus high growth potential, and make sure that economic policy is consistent with the needs of these sectors. It is not about picking winners, nor about fiscal incentives (as in the infant industry proposal). What is important is to direct the scarce government attention and political capital towards policies that are particularly important for the growth of the promising sectors. This, for instance, is what lies behind the Costa Rican program to strengthen the technical schools in the areas of informatics, electronics and 
metal working and mold making. This is also the rationale for its program to support the development of local suppliers to high tech multinationals.

Sixth, one of the factors that makes one think that the Costa Rican strategy will be maintained at least in the medium term is that the responsibility is spread among many different actors in society. It is not only the Government that is running programs to strengthen the technical capacity of the country, but several other organizations are also helping, among them public universities, industry chambers, technical schools, and CINDE.

Seventh, the case of Intel's decision to invest in Costa Rica shows very clearly the importance of transportation logistics for high tech companies, whose products exhibit high rates of innovation (and thus require fast shipment of goods from factory to consumers) and a high value relative to size and weight. High quality airport systems and friendly and open policies towards air travel and cargo companies seem very advisable.

And finally, rather than give special concessions to particular companies to lure them to invest in the country, it is more advisable to adopt policies and implement reforms that are of general applicability but that are particularly important for the companies whose investment is being promoted. 


\section{References}

- ARC (Applied Research and Consulting) (1999). "Foreign Investment in Costa Rica and Other Development Countries." CINDE. Mimeographed. San José.

- FIAS (1996). “A Strategy for Foreign Investment in Costa Rica's Electronics Industry." Mimeographed. Washington D.C.: World Bank.

- Larraín, F., López-Calva, F. and A. Rodríguez-Clare (2001). “Intel: A Case Study of Foreign Direct Investment in Central America," chapter 6 in ed. Felipe Larraín, Economic Development in Central America, vol. I: Growth and Internationalization. Harvard University Press.

- Spar, D. (1998). “Attracting High Technology Investment: Intel's Costa Rican Plant," FIAS Occasional Paper 11. Washington D.C.: World Bank. 